Professeur Tilman B. Drüeke Bernard Moinier
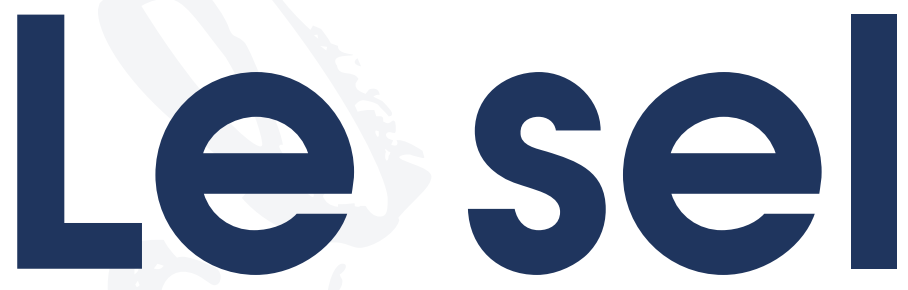

\title{
dans TOUS SES ÉTATS
}

VRAI/FAUX

sur un aliment trop critiqué 


\section{Collection Alimentation et Santé dirigée par le Dr H. Robert}

La collection Alimentation et Santé fait le point des connaissances actuelles sur des aliments utilisés quotidiennement par les consommateurs.

Destinée aux professionnels de la nutrition mais également à un public plus large soucieux de son alimentation, chaque ouvrage présente un aliment dans sa globalité, de son élaboration aux conséquences de sa consommation sur la santé. Sans parti pris et appuyée par des études médicales sérieuses, cette collection permet également de rétablir certaines contre-vérités ou idées reçues largement diffusées auprès du public.

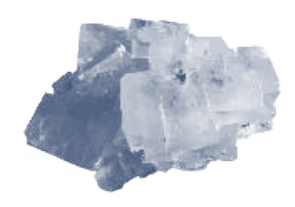

Imprimé en France

ISBN : 978-2-7598-1706-1

Tous droits de traduction, d'adaptation et de reproduction par tous procédés, réservés pour tous pays. La loi du 11 mars 1957 n'autorisant, aux termes des alinéas 2 et 3 de l'article 41, d'une part, que les « copies ou reproductions strictement réservées à l'usage privé du copiste et non destinées à une utilisation collective », et d'autre part, que les analyses et les courtes citations dans un but d'exemple et d'illustration, « toute représentation intégrale, ou partielle, faite sans le consentement de l'auteur ou de ses ayants droit ou ayants cause est illicite » (alinéa $1^{\text {er }}$ de l'article 40). Cette représentation ou reproduction, par quelque procédé que ce soit, constituerait donc une contrefaçon sanctionnée par les articles 425 et suivants du code pénal. 